\title{
THE EFFECT OF THICKNESS AND DEGREE OF TRANSLUCENCY ON THE FINAL COLOR OF LITHIUM DISILICATE VENEERS
}

\author{
Shereen A Nossair*
}

\begin{abstract}
Statement of problem: Achieving lighter final shades of A1 and BL1 with lithium disilicate veneers and the impact of different lithium disilicate translucencies and thickness on the final color is unclear. Aim: The aim of this in vitro study was to investigate the effect of different translucencies and thicknesses of lithium disilicate on the final shade of veneers.

Materials and methods: Eighty lithium disilicate specimens were fabricated from two translucencies of lithium disilicate blocks(IPS e.max CAD blocks, Ivoclar Vivadent); HT high translucency(HT) and low translucency (LT), in two different shades; A1 and BL1, and with 4 different thicknesses; $0.3 \mathrm{~mm}, 0.5 \mathrm{~mm}, 0.7 \mathrm{~mm}$, and $0.9 \mathrm{~mm}$. The discs were placed on an A3 shade composite substrate with a $0.1 \mathrm{~mm}$ translucent resin cement. $\Delta \mathrm{E}$ values were recorded to determine color differences between the specimens and the standard A1 and BL1 color parameters. $\Delta \mathrm{E}$ values were directly recorded with a handheld spectrophotometer (Easyshade Advance) The $\Delta \mathrm{E}$ values were compared with an acceptability threshold $(\Delta \mathrm{E}=3.7)$. Two-way ANOVA, and the Bonferroni test were used to analyze data $(\alpha=.05)$.
\end{abstract}

Results: The changes in both thickness and translucency showed high significance. For A1 shade, the $0.9 \mathrm{~mm}$ LT showed the least mean $\Delta \mathrm{E}$ value while the highest mean value was obtained by $0.9 \mathrm{~mm}$ HT. For BL1 shade, The $0.9 \mathrm{~mm}$ HT samples showed the least mean $\Delta \mathrm{E}$ value while the highest mean value was obtained by $0.3 \mathrm{~mm}$ LT samples.

Conclusions: The thickness and the translucency of lithium disilicate affected its final color. A minimum of $0.5 \mathrm{~mm}$ thickness of LT lithium disilicate was able to produce a clinically acceptable A1 shade. Achieving BL1 final shade was not possible with both HT lithium disilicate and LT lithium disilicate in thicknesses up to $0.9 \mathrm{~mm}$.

\section{INTRODUCTION}

Conservative or minimally invasive esthetic restorations have become increasingly popular among patients seeking esthetic rehabilitation of the ante- rior region. The advances in ceramics have enabled the fabrication of such minimal preparation restorations such as veneers for patients with discoloration, malpositioning, spacing, problems of proportion and size of the teeth. ${ }^{1,2,3}$ Newer generations of

* Lecturer, Department of Fixed Prosthodontics, Future University in Egypt 
all-ceramic systems and adhesive cements allow dentists to use a minimally invasive approach with conservative preparations of thicknesses ranging from 0.5 to $2 \mathrm{~mm} .{ }^{4}$ Laminate veneers may even permit preparations of $0.3-0.7 \mathrm{~mm}$ thickness to limit preparations within enamel to ensure efficient adhesive cementation. ${ }^{5}$

However, the thinner ceramic restorations can make masking underlying teeth color difficult due to the translucency of the ceramic and the resultant exposure through the ceramic material of the polymerized resin cement or tooth structure. Furthermore, lighter shades and bleached shades, which are popularly preferred among patients, become more challenging to reach with thin ceramics.It is possible to improve the masking ability of ceramic veneers by increasing their thickness ${ }^{6}$ although, this would require an increased amount of tooth reduction. Using different shades and opacities of cements to mask underlying tooth color is also possible.

Begum et $\mathrm{al}^{7}$ concluded in their study that the color masking ability of a $0.5-\mathrm{mm}$ veneer with an opaque shade of resin cement could be similar to a $1.0-\mathrm{mm}$ veneer with a translucent shade of resin cement, thus being more conservative.

Lithium disilicate (IPS eMax CAD Ivoclar Vivadent, Schaan, Liechtenstein) is one of the most commonly used glass ceramics for fabrication of laminate veneers. Owing to its excellent esthetic properties coupled with adequate strength, ${ }^{8,9}$ and bonding capacities ${ }^{10}$, enabling them to be used in thin veneers ${ }^{11}$. By producing a material where the lithium disilicate crystalline phase and the glassy phase possess a similar index of refraction, it is possible to produce the highly translucent formulation of the material ${ }^{12}$.

Although the translucency of lithium disilicate glass ceramic is considered an advantage, the translucency can have a negative effect on the resulting color because of shadowing underlying tooth color. The originally heat pressed ceramic, is available also as partially sintered blocks for CAD/CAM milling. Besides coming in a wide variety of colors, IPS eMax CAD is also available in different levels of translucency or opacity; high translucency (HT), medium translucency (MT), low translucency (LT) and medium opacity (MO). This variation is accomplished via differences in the microstructure of the material. Two levels of translucency may be acquired based on the precrystallization treatment of the CAD/CAM ceramic blocks: high-translucency (HT) and low-translucency (LT) material. ${ }^{13}$ Both formulations have identical crystal content but differ in crystal sizes, with HT ceramic exhibiting crystals of $1.5 \times 0.8 \mathrm{~mm}$ dispersed in a glassy matrix, whereas LT ceramic exhibits smaller crystals $(0.8 \times 0.2 \mathrm{~mm})$ in a higher density matrix..$^{14}$

IPS e.max CAD is available in the standard A through D shades and also includes a line of bleach shades. Like most dental ceramics, the color of the material is determined by colorant ions dispersed in the matrix ${ }^{15}$. While conservation of tooth structure is a main goal, a superior esthetic result necessitates either matching adjacent natural dentition or achieving the desired final color, especially lighter shades, as A1 shade, which is the most commonly selected shade by patients. ${ }^{16,17}$

The final color of ceramic restoration is a result of several interacting factors; ceramic thickness and translucency, substrate color and the thickness and color of the cement. ${ }^{18,19,20,21,22}$ Since the typical thickness of a veneer is usually much larger than the cement thickness, the degree of veneer translucency was found to be more effective in masking the underlying discolored substrate than the luting agent shade. ${ }^{23}$ Inspite of the well documented color modifying effect of luting cements, several authors agree that the choice of cement color has less of an effect on the final color of restorations..$^{18,24,25}$ The effect of different thicknesses of lithium disilicate have been previously investigated in thickness ranging from 0.3-2.5 mm. Most reported a significant decrease in $\Delta \mathrm{E}$ value with increase in thickness. ${ }^{7,18,26,27}$ 
Ali et $\mathrm{a}^{28}$ recorded highest $\Delta \mathrm{E}$ values with $\mathrm{HT}$ lithium disilicate in BL1 shade with darker substrates. Czigola et al ${ }^{19}$ demonstrated that crowns with greater translucency recorded higher $\Delta \mathrm{E}$ values resulting in a lower quality shade match. Nonetheless, the results of HT crowns on yellowish substrates showed a decreasing $\Delta \mathrm{E}$-despite the decreasing lightness of the shade (ND1-ND6) though $\Delta \mathrm{E}$ increase was expected since HT crowns are more translucent. This phenomenon demonstrates the complexity of the optical properties of these materials.

There is not enough available information or recommendations for the production of desired lighter and bleached shades by lithium disilicate ceramics. Therefore, the purpose of this in vitro study was to evaluate the color difference $(\Delta \mathrm{E})$ from standard A1 and BL1 color parameters and corresponding shades of lithium disilicate used in four different thicknesses $(0.3 \mathrm{~mm}, 0.5 \mathrm{~mm}, 0.7 \mathrm{~mm}$ and $0.9 \mathrm{~mm})$ and two translucencies of the lithium disilicate ceramic material, high translucency HT and low translucency LT (IPS e.max CAD).

\section{The null hypothesis proposed that:}

1. There would be no effect from the use of different translucencies of lithium disilicate on the final color of ceramic veneers, and

2. There would be no effect from the use of different thicknesses of different translucencies of lithium disilicate on the final color of ceramic veneers.

\section{MATERIALS AND METHODS}

A total of 80 ceramic discs were prepared from lithium disilicate CAD blocks (IPS e.max CAD blocks) in shades A1 and BL1 using both high translucency and low translucency blocks. The discs were divided into two main groups according to the shade of the blocks; shade A1 and shade BL1, 40 discs each. Each group was further subdi- vided into two subgroups according to the translucency of the lithium disilicate: Low translucency LT emax CAD and high translucency HT emax CAD; 20 discs each. Each subgroup was further subdivided into four divisions, 5 discs each, according to disc thickness: 0.3, 0.5, 0.7 and $0.9 \mathrm{~mm}$ thicknesses. $\Delta \mathrm{E}$ values were recorded to determine color differences between the specimens and the standard A1 and BL1 color parameters. $\triangle \mathrm{E}$ values were directly recorded with a handheld spectrophotometer (Easyshade Advance, VITA Zahnfabrik). The $\Delta \mathrm{E}$ values were compared with an acceptability threshold $(\Delta \mathrm{E}=3.7)$.

\section{Disc Preparation}

\section{I- Sectioning of IPS e.max CAD blocks:}

A total of 80 ceramic specimens were sectioned from IPS e.max CAD blocks in two different shades: A1 and BL1. Each shade was used in two different translucencies, LT-A1 (low translucent A1), HT-A1 (high translucent A1), LT-BL1 (low translucent bleach BL1) and HT-B1-1 (high translucent bleach BL1). IPS e.max CAD block size C14 $(14 \times 12 \times 16 \mathrm{~mm})$ was used. The blocks in each subgroup were cut into four different thicknesses using a slow-speed diamond saw (ISOMET 4000 microsaw, Buehler, USA) with a water-cooling system. A diamond disc of $0.7 \mathrm{~mm}$ thickness at a speed 2500 $\mathrm{rpm}$ and a feeding rate $5 \mathrm{~mm} / \mathrm{min}$ was used to obtain discs of approximately $0.3,0.5,0.7$ and $0.9 \mathrm{~mm}$ thickness of each translucency. All specimens were fabricated from the same batch to avoid the differences in color with different batches of the same porcelain system.

All specimens were finished flat using a wet \#120 grit silicon carbide sand paper to obtain the desired thickness from one side. From the other side they were finished flat using wet \#600, \#800, \#1000 \& \#1200-grit silicon carbide sand papers respectively by sliding each disc for 20 seconds using a light finger pressure on a line of $2 \mathrm{~cm}$ long on 
each grit to obtain a smooth surface ready for glazing. The dimensions of the specimens were kept at $(12 \mathrm{X} 14 \mathrm{~mm})$ with thickness levels of $(0.3 \pm 0.05$, $0.5 \pm 0.05,0.7 \pm 0.05$ and $0.9 \pm 0.05 \mathrm{~mm})$. A manual micrometer was used to measure the thickness of each specimen. The specimens were ultrasonically cleaned in distilled water for 10 minutes.

\section{II- Glazing:}

The specimens were then coated on the smooth finished side with a layer of neutral-shade glaze (IPS e.max CAD crystal/glaze paste), placed over cotton $\&$ honey combed firing tray with the glazed surface facing upward and fired at $820 / 840^{\circ} \mathrm{C}$ in Programat P300 (Ivoclar Vivadent) according to the manufacturer firing parameters, to obtain fully crystallized and glazed discs.

\section{Fabrication of the composite substrate:}

A composite substrate block shade A3, (Filtek Z250, 3M, USA) with the same dimensions as the ceramic specimens $(12 \mathrm{X} 14 \mathrm{~mm})$ and thickness $2 \mathrm{~mm}$ was fabricated using a mold. The mold was fabricated by placing a 2 -mm ceramic specimen (12 X 14 X $2 \mathrm{~mm}$ ) in a container filled with mixed polyvinyl siloxane impression material (Speedex putty; Coltène). A glass slab was placed on the top to form a space with the same dimension as the ceramic specimen. The composite was light cured incrementally for 20 seconds, and a glass microscopic slide was put on top to obtain a smooth surface and light cured for 40 seconds.

\section{Application of the cement to the composite substrate:}

A layer of translucent shade cement (Rely X Veneer, 3M, USA) was applied over the composite substrate. A thickness of $0.1 \mathrm{~mm}$ was controlled by pressing the surface of a glass microscopic slide with one end of a manual micrometer (Micrometer M110-50; Mitutoyo) after loading the cement onto the foundation block. The cement was completely polymerized using a photopolymerizing light cure over the cover glass for 90 seconds. The cover glass was then carefully separated from the cement, leaving the cement layer intact on the composite substrate block.

\section{Color measuring:}

The specimens were placed on the composite substrate without cementation. To reduce the edge loss effect (light within the specimen scattered to the edges without being absorbed), a drop of glycerin was placed between each specimen and the backing to seal the airspace and ensure that the specimen was in optical contact with the backing.

All the specimens were tested for color reproduction using a handheld spectrophotometer (EasyShade Advance)

All specimens were measured against the previously fabricated foundation (composite substrate +cement layer). Color measurements were performed by positioning the aperture of the portable spectrophotometer (5mm diameter) perpendicularly against the center of the flat ceramic surface of each specimen-substrate assembly. The aperture of the spectrophotometer was fully contacting the surface of the disc. Vita Easyshade was used in the "restoration mode" to determine the $\Delta \mathrm{E}$ of all the specimens. Three measurements were taken for each specimen. Vita Easyshade device was calibrated every two measurements in order to standardize reproducibility.

Analysis of Variance (ANOVA), both two way and one way were used in testing significance for the effect of thickness, translucency and their interactions on mean color parameters. Bonferroni's post-hoc test was used for pair-wise comparison when ANOVA test showed significance. The significance level was set at $\mathrm{P} \leq 0.05$. Statistical analysis was performed by IBM SPSS Statistics Version 17 for Windows. 


\section{RESULTS}

\section{Statistical Analysis of Shade A1 Reproduction}

The $0.9 \mathrm{~mm}$ LT showed the least mean $\Delta \mathrm{E}$ value while the highest mean value was obtained by 0.9 mm HT. The change of both the thickness and translucency of shade A1 showed high significance. Also the interaction between them was statistically highly significant. By using one way ANOVA and Bonferroni test for multiple comparisons to study the effect of the change in the thickness in each shade and translucency separately. Shade A1 LT specimens showed a statistically significant difference between all thicknesses. Also, for shade A1 HT specimens the comparisons between all thicknesses showed high significance (Table 1, Figure 1). A1 HT mean $\Delta \mathrm{E}$ values for all thicknesses were not within clinical acceptable levels. For A1 LT mean $\Delta \mathrm{E}$ values were within clinically acceptable levels except for $0.3 \mathrm{~mm}$ thickness.

TABLE (1) Means and standard deviations of $\Delta E$ of e.max CAD shade A1 low translucency (LT) and high translucency (HT)

\begin{tabular}{|c|c|c|c|}
\hline \multicolumn{4}{|c|}{ Delta E shade A1 } \\
\hline \multirow{2}{*}{ Thickness } & LD Translucency & Mean & St. Dev. \\
\hline \multirow{2}{*}{$0.3 \mathrm{~mm}$} & LT & 4.26 & 0.43 \\
\cline { 2 - 4 } $0.5 \mathrm{~mm}$ & HT & 4.06 & 0.17 \\
\cline { 2 - 4 } & LT & 3.19 & 0.35 \\
\hline \multirow{2}{*}{$0.7 \mathrm{~mm}$} & HT & 4.85 & 0.46 \\
\cline { 2 - 4 } & LT & 2.94 & 0.37 \\
\hline \multirow{2}{*}{$0.9 \mathrm{~mm}$} & HT & 6.61 & 0.13 \\
\cline { 2 - 5 } & LT & 2.49 & 0.32 \\
\hline
\end{tabular}

\section{Statistical Analysis of Shade BL1 Reproduction}

The $0.9 \mathrm{~mm}$ HT samples showed the least mean $\Delta \mathrm{E}$ value while the highest mean value was obtained by $0.3 \mathrm{~mm}$ LT samples. The change of both the thickness and translucency of shade BL1 showed high significance. Also the interaction between them was statistically highly significant. For shade BL1 low translucency samples only the transition between $0.3 \mathrm{~mm}$ samples and 0.5 $\mathrm{mm}$ samples showed non-significance. While that between all other thicknesses showed high significant differences (Table 2, Figure2). The results obtained from shade BL1 HT samples were all highly significant. All mean $\triangle \mathrm{E}$ values of BL1 in both HT and LT specimens were not within clinically acceptable levels.

By this, the null hypothesis was rejected, since both the translucency and thickness of lithium disilicate affected the final perceived color.

TABLE (2) Means and standard deviations of $\Delta E$ of e.max CAD shade BL1, low translucency (LT) and high translucency (HT)

\begin{tabular}{|c|c|c|c|}
\hline \multicolumn{4}{|c|}{ Delta E Shade BL1 } \\
\hline \multirow{2}{*}{ Thickness } & LD Translucency & Mean & St. Dev. \\
\hline \multirow{2}{*}{$0.3 \mathrm{~mm}$} & LT & 14.19 & 1.26 \\
\cline { 2 - 4 } & HT & 12.05 & 0.76 \\
\hline \multirow{2}{*}{$0.5 \mathrm{~mm}$} & LT & 13.22 & 1.7 \\
\cline { 2 - 4 } & HT & 9.07 & 0.52 \\
\hline \multirow{2}{*}{$0.7 \mathrm{~mm}$} & LT & 8.7 & 1.05 \\
\cline { 2 - 4 } & HT & 6.26 & 0.19 \\
\hline \multirow{2}{*}{$0.9 \mathrm{~mm}$} & LT & 5.58 & 0.94 \\
\cline { 2 - 4 } & HT & 5.02 & 0.29 \\
\hline
\end{tabular}




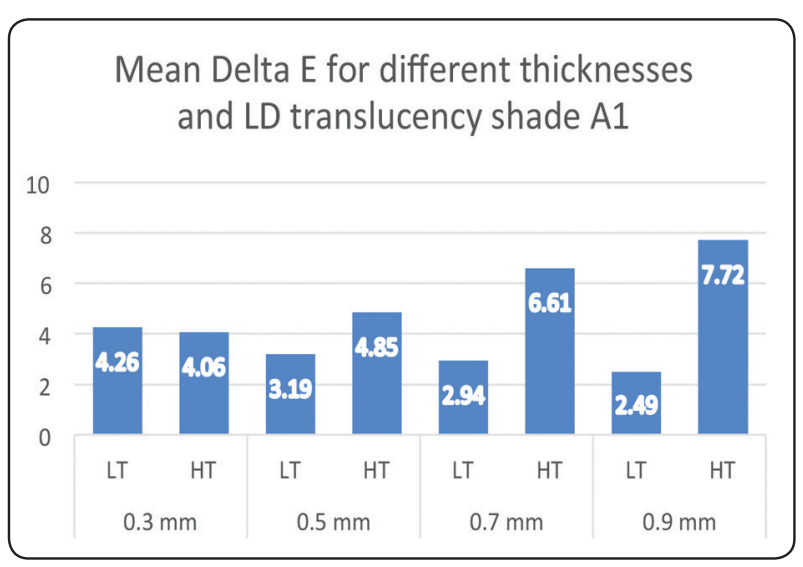

Fig. (1) Mean $\Delta \mathrm{E}$ for different thicknesses and LD translucency shade $\mathrm{A} 1$

\section{DISCUSSION}

The challenge of maintaining a conservative preparation for esthetic veneers within enamel while obtaining a predictable change in the final shade of the teeth is a complex procedure. In addition, masking underlying tooth color to satisfy the popular demand of patients for lighter teeth, further complicates the procedure.

The different translucencies of glass ceramics are available to give the dentist the ability to choose the degree of masking/show through of underlying tooth color to achieve the desired final shade. Culp and Mclaren even state that "translucency properties of IPS ${ }^{\mathrm{TM}}$ e.Max CAD in both the HT and LT formulation, make it possible to place margins that blend with adjacent dentition, effectively masking the edges of the restoration" ${ }^{29}$.

Although reaching the desired shade is predominantly dependent on the nature of the ceramic ${ }^{23}$, the thickness of the ceramic and the cement shade can improve the masking ability of a ceramic restoration. Hence, this study was designed to evaluate the effect of changing the thickness and translucency of lighter shades of lithium disilicate ceramics (IPS e.max $\mathrm{CAD}$ ) on the resultant final shade of the veneer, allowing the predictability of the final results without depending on the shade of the cement to

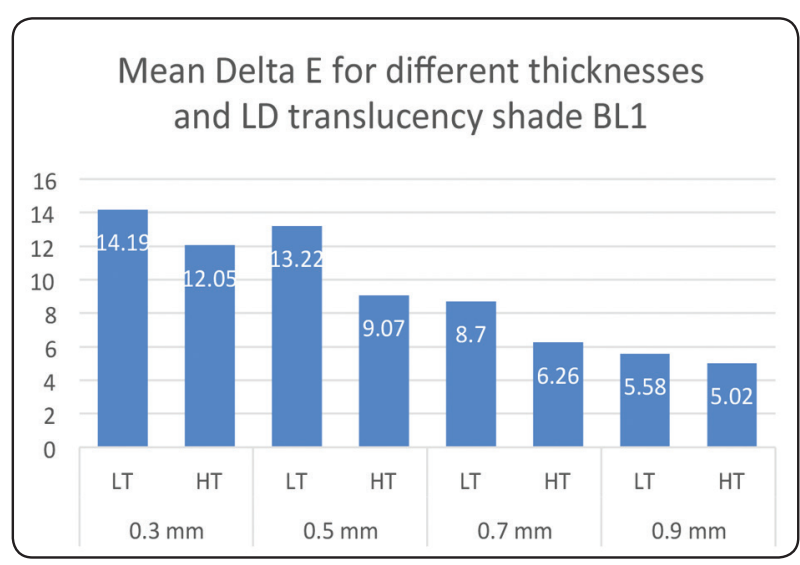

Fig. (2) Mean $\Delta \mathrm{E}$ for different thicknesses and LD translucency shade BL1

mask the shade of the underlying abutment. This may assist in determining the amount of reduction necessary and the translucency of ceramic needed when contemplating a final shade of A1 or BL1.

Many studies have selected shade A1 for their research, as this tooth shade is the most commonly selected for ceramic restorations..$^{24,28,30}$ BL1 shade was selected as it is a lightest bleached shade available.

As the present study was designed to simulate veneers bonded to tooth substrates, ceramic specimens were chosen with thicknesses $0.3,0.5,0.7$ and $0.9 \mathrm{~mm}$ to simulate typical veneer restorations. 31,32,33 ISO suggests specimen thickness of $1 \mathrm{~mm}$ for composites and $0.3 \mathrm{~mm}$ for ceramics when measuring their masking ability. ${ }^{34} \mathrm{An}$ underlying tooth colored composite resin substrate of $2 \mathrm{~mm}$ thickness in shade A3 was used to simulate common undiscolored tooth substrates..$^{35}$

Cement layer thickness was chosen at $0.1 \mathrm{~mm}$, which is the suitable cement thickness to ensure adequate internal fit of the veneers ${ }^{36}$ RelyX veneer cement was chosen in this study as a representative of light cured resin cements recommended for cementation of anterior esthetic restorations. A translucent shade cement was used in this study to evaluate the impact of the ceramic per se without the 
modifying effect of the cement shade on the final shade. It is worth mentioning that increasing even white opaque cement layer thickness from 100 to $300 \mu \mathrm{m}$ did not affect the shade of lithium-disilicate restorations..$^{22}$

Most studies on masking ability of different dental materials have used dental spectrophotometers for color measurements ${ }^{18,37,38}$ Spectrophotometers are among the most accurate tools for tooth color measurement in dentistry. ${ }^{39}$ It is also not susceptible to being affected by environmental color factors, as is the human eye..$^{40}$ The color measurements in this study were done using an intraoral spectrophotometer EasyShade Advance, using "restoration mode" to compare the specimens with the corresponding stored color coordinate values of the A1 and BL1 (Ivoclar, Vivadent), in order to calculate the $\Delta \mathrm{E}$.

A drop of glycerin was placed between each specimen and the backing to seal the airspace and ensure the specimen was in optical contact with the backing to reduce the edge loss effect. ${ }^{22}$

Glycerin was used in this study as its refraction index is similar to porcelain, minimizing the light refraction that occurs when the light beam crosses substrates with different refractive indices as air and porcelain. ${ }^{41}$

The perceptibility and acceptability thresholds varied among the literature for various reasons. I. Ruyter et al. ${ }^{42}$ 1987, referred to it to be $3.3, \mathrm{~W}$. Johnston and $\mathrm{E} . \mathrm{Kao}^{43}$ in 1989 , referred to its value as being 3.7, J. Ragain and W. Johnston ${ }^{44}$ in 2000, reduced it to be $2.7, \mathrm{~S}$. Azer et al. ${ }^{45}$ mentioned that there is a lack of understanding of the color system, in addition to lack of a precise methodology to quantify color. Color assessment is considered a complex psycho-physiologic process that is subject to numerous variables. Also the available shade guides, in addition to minor differences in light conditions, have been found to dramatically affect the outcome of restoration color and the production of an acceptable color match. Light source for dental procedures should be diffuse and comfortable to the eyes, and should be compatible with the light source in the dental laboratory. They reported that perceivable color differences ranged from 1 to 2, whereas acceptable color differences for dental professionals ranged from 2.6 to 3.7. Douglas et $\mathrm{al}^{46}$ in 2007, $50 \%$ of the dentist observers could perceive a color difference of $2.6 \Delta \mathrm{E}$, and $50 \%$ of these observers would remake the restoration because of color mismatch (clinically unacceptable color match) with $5.5 \Delta \mathrm{E}$, and Da Silva et al. ${ }^{47}$ in 2008 , lowered it to be 2.67 . In this study $3.7 \Delta \mathrm{E}$ was set as it was the maximum acceptable color difference. ${ }^{43}$

The null hypothesis proposed was rejected since the results of this investigation indicate that both the thickness and the translucency of lithium disilicate affected the final shade of veneers. The results of shade A1 samples showed that the change in both the thickness and the translucency of the specimens had a highly significant effect on the final color of the restoration. A decrease in the mean $\Delta \mathrm{E}$ of shade A1 LT samples was observed with the increase in the thickness, this may be attributed to the increase in the opacity and saturation of color with the increase in the thickness of the ceramic layer. On the other hand there was an increase in the mean $\Delta \mathrm{E}$ of the A1 HT specimens with the increase of the thickness. This may be attributed to the high translucency of these specimens, and their chameleon effect, which means that the ceramic reflects the shade of the surrounding dentition. Czigola et al ${ }^{19}$ found that ceramic thickness has less of an effect if the material is highly translucent. It is worth mentioning, that HT blocks exhibit a higher translucency and lower brightness value than do LT blocks which have been characterized by their high level of brightness and true-to-nature chroma. ${ }^{5}$ Specimens of shade A1 LT with thicknesses of $0.5 \mathrm{~mm}$ and above were able to match A1 standard shade within the acceptable clinical range. While none of the A1 HT samples were within the acceptable clinical range. 
In the BL1 specimens, a gradual decrease in the mean $\Delta \mathrm{E}$ with the increase of the thickness was observed in both LT and HT.The possible reason for the high $\triangle \mathrm{E}$ values in the HT BL1 group may be the combined effect of the HT and the A3 substrate. Our results are in agreement with the findings of previous studies ${ }^{48,}{ }^{49},{ }^{50}$ which pointed out that increased thicknesses of ceramics will better mask a discolored substrate. None of the BL1 specimens were within clinically acceptable range. Bagis and Turgut 16 investigated the ability of glass ceramics at 0.5 $\mathrm{mm}$ thickness to match the color of shade guides. Their results showed that none of the full-ceramic systems was able to match the color of the shade guide. An additional possibility is the nature of the BL1 shade, which possesses less chroma than the other shades. ${ }^{28}$

For both A1 and BL1 shades, none of the HT specimens was in the clinically acceptable range. These results indicate that the substantial shade transformations was not possible in HT lithium disilicate in the thickness investigated in this study 0.3$0.9 \mathrm{~mm}$. These results are similar to those recorded for HT crowns by Czigola et al. ${ }^{19}$ The reason might be the material's optical properties: LT blocks have more lithium-disilicate crystals than HT blocks. Crystals reduce the internal scattering of light as it passes through the material. That means when the substrate has a dark color or the underlying tooth is much darker than the contemplated final shade of the restoration, the application of a CAD/CAM lithium disilicate with a HT ceramic block may result in limited success. ${ }^{18,25,51,52}$

Achieving a shade transition from shade A3 to shade BL1 was not attainable in thicknesses up to $0.9 \mathrm{~mm}$. Such a substantial shade transition apparently would require an increased thickness of the veneer, and excessive removal of tooth structure is needed to allow room for the increase in the thickness of the veneer. Pires et al ${ }^{30}$ compared HO (highopacity) and LO ceramics and found $\triangle \mathrm{E} 00$ values of ceramic $\mathrm{HO}$ to be lower than those of ceramic LT. Clinicians should consider increasing the thickness and opacity of the ceramic to mask the underlying color. ${ }^{30}$ In many studies, increasing ceramic thickness is accompanied by better color results. ${ }^{18,22,25,28}$

A possible whitening of the tooth substrates should be considered before teeth reduction to decrease the difference in the shade of the abutment teeth and the required final shade. Accordingly, the results of this investigation indicate that achieving final bleached shades with minimal preparation veneers was not be possible in both HT and LT CAD lithium disilicate.

\section{CONCLUSIONS}

Both the thickness and different translucencies had a significant effect on the final shade of CAD lithium disilicate.

Achieving a shade transition from A3 to A1 using LT lithium disilicate was possible in the minimum thicknesses of $0.5 \mathrm{~mm}$, and was not possible using HT lithium disilicate in thicknesses up to $0.9 \mathrm{~mm}$.

Achieving a shade transition from $\mathrm{A} 3$ to $\mathrm{BL} 1$ was not possible in thicknesses of $0.3-0.9 \mathrm{~mm}$ in both HT and LT lithium disilucate.

\section{REFERENCES}

1 Da Cunha LF, Reis R, Santana L, Romanini JC, Carvalho RM, Furuse AY. Ceramic veneers with minimum preparation. Eur J Dent 2013;7:492-6.

2 Okida RC, Filho AJ, Barao VA, Dos Santos DM, Goiato $\mathrm{MC}$. The use of fragments of thin veneers as a restorative therapy for anterior teeth disharmony: A case report with 3 years of follow-up. J Contemp Dent Pract 2012;13:416-20.

3 Kamble VD, Parkhedkar RD. Esthetic rehabilitation of discolored anterior teeth with porcelain veneers. Contemp Clin Dent 2013;4:124-6.

4 Pinto RC, Chambrone L, Colombini BL, Ishikiriama SK, Britto IM, Romito GA. Minimally invasive esthetic therapy: a case report describing the advantages of a multidisciplinary approach. Quintessence Int 2013;44: 385-391. 
5 Turgut S, Bagis B. Effect of resin cement and ceramic thickness on final color of laminate veneers: An in vitro study. J Prosthet Dent 2013;109:179-86.

6 Shono NN, Al Nahedh HN. Contrast ratio and masking ability of three ceramic veneering materials. Oper Dent 2012;37:406-16.

7 Begum Z, Chheda P, Shruthi CS, Sonika R. Effect of Ceramic Thickness and Luting Agent Shade on the Color Masking Ability of Laminate Veneers. The Journal of Indian Prosthodontic Society. 2014; 14(1):46-50.

8 F. Zarone, M. Ferrari, F.G. Mangano, R. Leone, R. Sorrentino. Digitally oriented materials: focus on lithium disilicate ceramics Int J Dent, 2016 ; 98.

9 Giordano R, McLaren EA. Ceramics overview: classification by micro- structure and processing methods. Compend Contin Educ Dent. 2010; 31:682-684.

10 Aboushelib MN, Sleem D. Microtensile bond strength of lithium disilicate ceramics to resin adhesives. J Adhes Dent. 2014;16(6):547-52.

11 Schmitter M1, Seydler B B. Minimally invasive lithium disilicate ceramic veneers fabricated using chairside CAD/CAM: a clinical report. J Prosthet Dent. 2012; 107(2):71-4.

12 X.P. Luo, L. Zhang. Effect of veneering techniques on color and translucency of Y-TZP. J Prosthodont. 2010;19: 465-470.

13 Höland W, Ritzberger C, Apel E. Formation and crystal growth of needle-like fluoroapatite in functional glassceramics. J Mater Chem 2008; 18: 1318- 1332

14 Denry, J. Holloway Ceramics for dental applications: a review. Materials. 2010;3: 351-368.

15 Li RW, Chow TW, Matinlinna JP. Ceramic dental biomaterials and CAD/CAM technology: state of the art. J Prosthodont Res 2014;58:208e16

16 Bagis B, Turgut S. Optical properties of current ceramics systems for laminate veneers. J Dent. 2013;41:24-30.

17 Wee AG, Monaghan P, Johnston WM. Variation in color between intended matched shade and fabricated shade of dental porcelain. J Prosthet Dent. 2002;87:657-666.

18 Chaiyabutr Y, Kois JC, Lebeau D, Nunokawa G. Effect of abutment tooth color, cement color, and ceramic thickness on the resulting optical color of a CAD/CAM glass-ceramic lithium disilicate reinforced crown. J Prosthet Dent. 2011;105:83-90.
19 Czigola A, Abram E, Kovacs ZI, Marton K, Hermann P, Borbely J. Effects of substrate, ceramic thickness, translucency, and cement shade on the color of CAD/CAM lithium-disilicate crowns. J Esthet Restor Dent. 2019;1-8.

20 Gunal B and Ulusoy MM. Optical properties of contemporary monolithic CAD-CAM restorative materials at different thicknesses. Journal of Esthetic and Restorative Dentistry. 2018; 30(4): 2018(5):434-441.

21 Azer SS, Rosenstiel SF, Seghi RR, Johnston WM. Effect of substrate shades on the color of ceramic laminate veneers. J prosthet Dent 2011;106:179-183.

22 Niu E, Agustin M, Douglas RD: Color match of machinable lithium disilicate ceramics: effects of cement color and thickness. J Prosthet Dent 2014;111:42-50.

23 Bassem S. M. Kandil, Amena M. Hamdy, Ahmed K. Aboelfadl and Mohamed I. El-Anwar. Effect of ceramic translucency and luting cement shade on the color masking ability of laminate veneers. Dental research journal. 2019: 16(3): 192-199.

24 Dozic A, Tsagkari M, Khashayar G, Aboushelib M. Color management of porcelainveneers: influence of dentin and resin cement colors. Quintessence Int. 2010;41:567-573.

25 Vichi A, Ferrari M, Davidson CL. Influence of ceramic and cement thickness on the masking of various types of opaque posts. J Prosthet Dent. 2000;83:412-417.

26 Pires LA, Novais PM, Araújo VD, Pegoraro LF. Effects of the type and thickness of ceramic, substrate, and cement on the optical color of a lithium disilicate ceramic. The Journal of Prosthetic Dentistry. 2017; 117(1):144-149.

27 Alqahtani MQ, Aljurais RM, Alshaafi MM. The effects of different shades of resin luting cement on the color of ceramic veneers. Dental materials journal. 2012; 31(3): 354-61.

28 Abdulaziz Al Ben Ali A, Kang K, Finkelman MD, Zandparsa R, Hirayama H.The effect of variations in translucency and background on color differences in CAD/ CAM lithium disilicate glass ceramics. J Prosthodont 2014;23:213-220.

29 L. Culp, E.A. McLaren. Lithium disilicate: the restorative material of multiple options Comp Contin Educ Dent. 2010; 31: 716-720.

30 Paravina RD, Ghinea R, Herrera LJ, et al. Color difference thresholds in dentistry.J Esthet Restor Dent. 2015;27:1-9. 
31 S. Duarte, E. Vilarreal, T. Tada and J. Phark. Sandwich Technique for Minimal Invasive Bonded Porcelain Veneers. DMG, user report, 2008(Jul): 1-3.

$32 \mathrm{~J}$ Fondriest and $\mathrm{M}$ Roberts. Changing Brightness with Low-Preparation Veneers. Inside Dentistry. 2010;6(3).

33 P. Newsome and S. Owen. Longevity of Ceramic Veneers in General Dental Practice. Aesthet. Dent. Today. 2009; 3(3): 6-10.

34 International Organization for Standardization. ISO/TR 28642: Dentistry - guidance on colour measurement. Geneva: International Organization for Standardization; 2016.

35 W. Xing, T. Jiang, X. Ma, S. Liang, Z. Wang, Y. Sa, and Y. Wang, Evaluation of The Esthetic Effect of Resin Cements and Try-in Pastes on Ceromer Veneers. J. Dent.2010, 38 (2): 87-94.

36 S. Ishikawa-Nagai, J. Chang, J. Da Silva, M. Sakai and J. Kristiansen. The Optical Effect of Composite Luting Cement on All Ceramic Crowns. J. Dent. 2009; 37: 937-943.

37 Farhan D, Sukumar S, von Stein-Lausnitz A, Aarabi G, Alawneh A, Reissmann DR. Masking ability of bi- and tri- laminate all-ceramic veneers on tooth-colored ceramic discs. J Esthet Restor Dent 2014; 26:232-9.

38 Soim A, Strîmbu M, Burde AV, Culic B, Dudea D, Gasparik C. Translucency and masking properties of two ceramic materials for heat-press technology. J Esthet Restor Dent 2018;30(2): 18-23.

39 Luo W, Westland S, Ellwood R, pretty I, Cheung V. Development of a whiteness index for dentistry. J Dent 2009;37(1):e21-e26.

40 Della Bona A, Barrett AA, Rosa V, Pinzetta C. Visual and instrumental agreement in dental shade selection: three distinct observer popu- lations and shade matching protocols. Dent Mater 2009;25: 276-281.

41 H. Omar, O. Atta, O. El-Mowafy, and S. Khan, Effect of CAD-CAM Porcelain Veneers Thickness on Their Cemented Color. J. Dent.2010, 38(2): 95-99.
42 I. Ruyter, K. Nilner, and B. Moiler. Color Stability of Dental Composite Resin Materials for Crown and Bridge Veneers. Dent Mater. 1987;3: 246-251.

43 W. Johnston and E. Kao, "Assessment of Appearance Match by Visual Observation and Clinical Colorimetry. J. Dent. Res. 1989, 68(5): p 819-822.

44 J. Ragain and W. Johnston. Color Acceptance of Direct Dental Restorative Materials by Human Observers Color Res App. 2000 (4): 278-285.

45 S Azer, G Ayash, W Johnston, M Khalil, and S. Rosenstiel. Effect of Esthetic Core Shades on The Final Color of IPS Empress All-Ceramic Crowns. J Prosthet Dent. 2006; 96: 397-401.

46 R. Douglas, T. Steinhauer, and A. Wee. Intra-Oral Determination of the Tolerance of Dentists for Perceptibility and Acceptability of Shade Mismatch. J Prosthet Dent. 2007; 97: 200-8

47 J. Da Silva, S. Park, H. Weber, and S. Ishikawa-Nagai. Clinical Performance of a Newly Developed Spectrophotometric System on Tooth Color Reproduction. J Prosthet Dent. 2008; 99: 361-368.

48 Peixoto RT, Paulinelli VM, Sander HH, Lanza MD, Cury LA and Poletto LT. Light transmission through porcelain. Dent Mater. 2007;23: 1363-8.

49 Lim HN, Yu B and Lee YK. Spectroradiometric and spectrophotometric translucency of ceramic materials. J Prosthet Dent. 2010;104:239-46.

50 Wang F, Takahashi H and Iwasaki N. Translucency of dental ceramics with different thicknesses. J Prosthet Dent. 2013;110:14-20.

51 Kürklü D, Azer SS, Yilmaz B and Johnston WM. Porcelain thickness and cement shade effects on the colour and translucency of porcelain veneering materials. J Dent. 2013;41:1043-1050

52 Chang J, Da Saliva JD, Sakai M, Kristiansen J and Ishikawa-Nagai S. The optical effect of composite luting cement on all ceramic crowns. J Dent. 2009;37:937-943. 